\title{
GABA as the pallidothalamic neurotransmitter: implications for basal ganglia function
}

JOHN B. PENNEY, JR. and ANNE B. YOUNG

Department of Neurology, University of Michigan, Ann Arbor, Mich. 48109 (U.S.A.)

(Accepted September 18th, 1980)

Key words: GABA - entopeduncular nucleus - globus pallidus - Huntington's chorea

GABA levels, high affinity GABA uptake and glutamic acid decarboxylase levels are reduced in rat ventroanterolateral thalamic nucleus after destruction of the entopeduncular nucleus with kainic acid. This is strong evidence that GABA is an entopedunculothalamic neurotransmitter. The striatoentopeduncular pathway is also GABAergic. Thus the function of the corpus striatum may be to disinhibit the thalamus.

The abnormal involuntary movements seen in Huntington's disease, Parkinson's disease, tardive dyskinesia and athetoid cerebral palsy are presumed to result in part from dysfunction of the neostriatum (caudate nucleus and putamen) ${ }^{1}$. These movements include chorea, athetosis, dystonia and bradykinesia. How neostriatal dysfunction leads to these symptoms is unknown. Except in Parkinson's disease, pharmacologic treatment of these abnormal movements has been disappointing. Occasionally, surgical therapy has proved successful especially when the surgical lesion is in the ventroanterior and ventrolateral nuclei (VL) of the thalamus ${ }^{3}$. The success of these operations suggests that these abnormal movements are dependent on the integrity of VL. The part of VL which projects to motor cortex receives a major output from the basal ganglia via the medial segment of the globus pallidus (MPS) (Fig. 1, left side) ${ }^{2,10}$. The MPS in turn receives output from neostriatal neurons which also send collaterals to the substantia nigra ${ }^{14}$. Thus these pathways from neostriatum to ventroanterior and ventrolateral thalamus via the medial pallidal segment may play an important role in the generation of abnormal movements. The neurotransmitter of medial pallidal cells is unknown. We have recently attempted to demonstrate the neurotransmitter of the pallidothalamic pathway in rats by studying neurotransmitter functions in ventrolateral nucleus of the thalamus after injection of kainic acid into the murine counterpart of the medial pallidal segment, the entopeduncular nucleus (EP).

Kainic acid (Sigma), 0.1 M solution, pH 7.0, was iontophoresed stereotaxically into the right EP of Sprague-Dawley rats $(150-200 \mathrm{~g})^{17}$. Stereotaxic coordinates were A.P. $-5.2 \mathrm{~mm}$, M.L. $-2.7 \mathrm{~mm}$, D.V. $-1.8 \mathrm{~mm}^{11}$. Angled injections from $30^{\circ}$ forward, passing through prefrontal cortex, striatum and globus pallidus, were used. Negative current ( $1 \mathrm{~mA}$ ) was passed through $40 \mu \mathrm{m}$ tip glass micropipettes with 500 
$\mathrm{msec}$ on $/ 500 \mathrm{msec}$ off pulses for $10 \mathrm{~min}^{8}$. Two weeks after injection, the animals were sacrificed by decapitation. The brains were rapidly removed and put into cold $0.32 \mathrm{M}$ buffered sucrose. Coronal sections $(1 \mathrm{~mm})$ were made through the diencephalon and punches one millimeter in diameter were taken bilaterally from the ventroanterolateral nucleus (the rat's equivalent of VL) (see Fig. 1). Punches were either frozen immediately on dry ice and stored at $-70^{\circ} \mathrm{C}$ for later determination of tissue amino acid levels or placed in the appropriate buffer and assayed for L-glutamate-1carboxylase (EC 4.1.15, GAD) ${ }^{6}$ or high affinity synaptosomal uptake ${ }^{20}$. Levels of amino acids were determined in ethanol extracts of the frozen punches by high performance liquid chromatography. Amino acid levels were determined fluorometrically as their $o$-phthaldialdehyde derivatives by a modification of previous techniques using a Spheri 5A 5- $\mathrm{C}_{18}$ reverse phase column (Brownlee) and a gradient from 22 to $40 \% \mathrm{~B}$ where $\mathrm{B}$ is methanol and $\mathrm{A}$ is $0.1 \mathrm{M}$ potassium acetate buffer $\mathrm{pH} 5.5$ plus $5 \%$ tetrahydrofuran 9,13 . The remainder of the slices and the rest of the brains were placed in $10 \%$ buffered formalin for one week. Sections of $40 \mu \mathrm{m}$ were then cut and stained with cresyl violet. Two rats were perfused and the brains processed according to the method of Fink and Heimer to demonstrate degenerating terminals ${ }^{5}$. Four rats were decorticated and assayed as above to control for the possibility that the pipettes or the kainic acid might also destroy fibers traveling through the lesion from cortex to ventroanterolateral nucleus.

Cresyl violet-stained sections revealed destruction of $50-90 \%$ of the entopeduncular neurons. Some lesions also involved the putamen, the amygdala or the lateral globus pallidus. Animals in which the lesion encroached on the thalamus or in which the punches were not entirely in VL were excluded.

The brains processed by the Fink-Heimer technique revealed degeneration in the thalamic nuclei to which the entopeduncular nucleus is thought to project: ventroanterolateralis, lateral habenula and parafasicularis ${ }^{2}$. There were also degenerating terminals in the subthalamic nucleus, lateral hypothalamus and bed nucleus of the stria terminalis presumably because lateral globus pallidus and amygdala were lesioned ${ }^{1,12}$.

Amino acid levels in ventroanterolateralis of the lesioned and unlesioned sides show no decrease in glycine, taurine, glutamate, aspartate, glutamine or threonine (Table I). There is a $54 \%$ decrease $(P<0.01)$ in the inhibitory amino acid, gammaaminobutyric acid (GABA). The decrease is very selective and so we also measured two other presynaptic GABAergic markers, glutamic acid decarboxylase (GAD) and high affinity GABA uptake in a series of similarly lesioned aninals. There is a $46 \%$ decrease in GAD $(P<0.01)$ and a $47 \%$ decrease in high affinity GABA uptake $(P<$ 0.01) (Table I). Animals with kainic acid lesions along the needle tract but not involving entopeduncular nucleus had no change in GAD in VL (lesioned side, $35.2 \pm$ $5.0 \mathrm{nmol} \mathrm{CO} / \mathrm{h} / \mathrm{mg}$ prot., control side, $39.6 \pm 9.4)$.

Some might argue that the decrease in GABAergic markers in thalamus results from the amygdalar, striatal or lateral pallidal lesions and not from the lesion of the entopeduncular cells. However, no projections from these nuclei to VL are known. If such projections exist they must be small in comparison to the projection from entopeduncular nucleus. 
TABLE I

$G A B A$ and $G A D$ levels and high affinity GABA uptake in ventroanterolateral thalamic nucleus of rats 2 weeks after unilateral injection of kainic acid into the entopeduncular nucleus

\begin{tabular}{|c|c|c|}
\hline & \multicolumn{2}{|c|}{ Ventroanterolateral thalamus } \\
\hline & Lesioned side & Control side \\
\hline \multicolumn{3}{|l|}{ Amino acid $(n=4)(\mu \mathrm{mol} / g$ wet weight $)$} \\
\hline Aspartate & $2.88 \pm 0.12$ & $2.62 \pm 0.20$ \\
\hline Glutamate & $15.1 \pm 2.0$ & $13.1 \pm 0.5$ \\
\hline Glutamine & $4.53 \pm 0.31$ & $4.26 \pm 0.29$ \\
\hline Glycine & $0.72 \pm 0.13$ & $0.78 \pm 0.14$ \\
\hline Threonine & $0.95 \pm 0.06$ & $1.00 \pm 0.06$ \\
\hline Taurine & $2.76 \pm 0.16$ & $2.89 \pm 0.06$ \\
\hline GABA & $0.94 \pm 0.14^{*}$ & $2.05 \pm 0.17$ \\
\hline$G A D(n=4)\left(\right.$ nmol $\mathrm{CO}_{2} / \mathrm{h} / \mathrm{mg}$ prot. $)$ & $23.1 \pm 3.2^{*}$ & $42.5 \pm 1.5$ \\
\hline GABA uptake $(n=4)($ nmol $/ 5$ min $/$ mg prot. $)$ & $0.17 \pm 0.04^{*}$ & $0.32 \pm 0.05$ \\
\hline
\end{tabular}

* $P<0.01$. Values represent the mean \pm the standard error of the mean of determinations on groups of 4 animals.

It is doubtful that the GABA changes in ventroanterolateralis are due to damage of corticothalamic pathways (Fig. 1, right side) by the pipette or by kainate since unilaterally decorticate animals show no change in GABA in ventroanterolateralis on the lesioned side (lesioned side, $2.72 \pm 0.29 \mu \mathrm{mol} / \mathrm{g}$; control side, $2.65 \pm 0.21$ ).

The medial pallidal segment receives a major input from GABAergic cells in the neostriatum ${ }^{14}$. If the GABAergic pallidothalamic cells receive GABAergic input from the striatopallidal cells there would be two sequential GABAergic inhibitory neurons connecting the striatum and the thalamus. The medial pallidal cells have been shown neurophysiologically to be tonically active ${ }^{7}$ and inhibitory onto thalamocortical cells in ventrolateralis ${ }^{19}$. It has not been established that striatopallidal cells make direct synaptic contact with pallidothalamic cells. If, however, such a connection exists, an active GABAergic output cell of the striatum would inhibit medial pallidal output cells thus 'disinhibiting' i.e. activating, certain thalamic cells ${ }^{16}$. A sequential order of striatomedialpallidal and pallidothalamic GABAergic neurons would explain the previously observed clinical phenomenon that low doses of GABA mimetic drugs reduce the chorea of Huntington's disease while higher doses are without effect ${ }^{18}$. The GABAergic striatopallidal cells degenerate in Huntington's disease ${ }^{15}$ and supersensitive GABA receptors develop in the globus pallidus ${ }^{4}$. Low doses of GABAergic agents might alleviate chorea by interacting preferentially with the supersensitive receptors in the pallidum while higher doses counteract this effect by actions in the thalamus.

In summary, GABAergic markers are reduced substantially in ventrolateral thalamus after selective destruction of the entopeduncular nucleus neurons in rat. The entopeduncular nucleus is the murine equivalent of the medial globus pallidus. We suggest that the inhibitory entopedunculothalamic neurons utilize GABA as a neurotransmitter. 


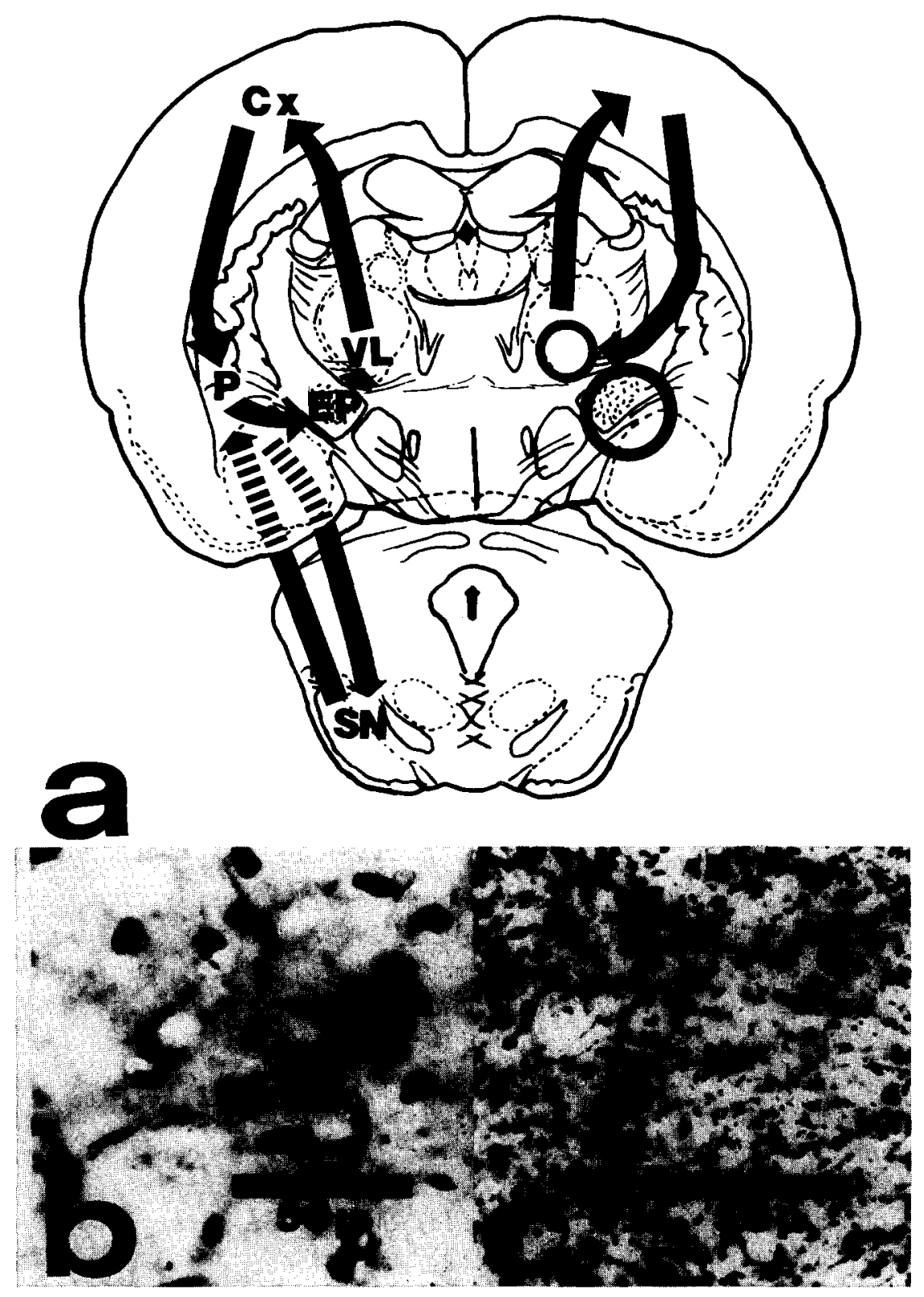

Fig. 1. Site of kainate lesion and punches. a: line drawing of the rostral surface of the rat brain slice from which $1 \mathrm{~mm}$ punches are taken. This is superimposed on a line drawing of the midbrain. Large circle shows the extent of a typical lesion. Small circle shows the site of the punches. Arrows show the direction of basal ganglia feedback loops: corticothalamic (right), corticostriatopallidothalamic (left) and striatonigral (bottom). Abbreviations: $\mathrm{Cx}$, cortex; $\mathrm{EP}$, entopeduncular nucleus; $\mathrm{P}$, putamen (striatum); SN, substantia nigra; VL, ventroanterolateral nucleus of thalamus. b: Fink-Heimer stain of VL from unlesioned side. Only cell nuclei take up the black stain. $\mathrm{c}$ : Fink-Heimer stain of VL from lesioned side. Degenerating fibers and axon terminals as well as nuclei take up the stain. 
Supported by USPHS Grants NS00464-01, NS00420-01 and NS15140-02, the United Cerebral Palsy Resea rch Foundation, the Committee to Combat Huntington's Disease and Michigan Memorial Phoenix Project Grant 567.

1 Carpenter, M. B., Human Neuroanatomy, 7th edn., Williams and Wilkins, Baltimore, 1976, pp. 512-520.

2 Carter, D. A. and Fibiger, H. C., The projections of the entopeduncular nucleus and globus pallidus in rat as demonstrated by autoradiography and horseradish peroxidase histochemistry, J. comp. Neurol., 177 (1978) 113-124.

3 Cooper, I. S., Involuntary Movement Disorders, Harper and Row, New York, 1969.

4 Enna, S. J., Bennett, J. P., Jr., Bylund, D. B., Snyder, S. H., Bird, E. D. and Iversen, L. L., Alterations of brain neurotransmitter receptor binding in Huntington's chorea, Brain Research, 116 (1976) 531-537.

5 Fink, R. P. and Heimer, L., Two methods for selective impregnation of degenerating axons and their synaptic endings in the central nervous system, Brain Research, 4 (1967) 369-374.

6 Fisher, S. K. and Davies, W. E., GABA and its related enzymes in the lower auditory system of the guinea pig, J. Neurochem., 27 (1976) 1145-1155.

7 Georgopoulous, A. P. and DeLong, M. R., The globus pallidus of the monkey: neuronal activity in relation to movement, Neurosci. Abstr., 4 (1978) 43.

8 Graybiel, A. M. and Devor, M., A microelectrophoretic delivery technique for use with horseradish peroxidase, Brain Research, 68 (1974) 167-173.

9 Hodgin, J. C., The separation of pre-column o-phthaldialdehyde derivatized amino acids by high performance liquid chromatography, J. liquid Chrom., 2 (1979) 1047-1059.

$10 \mathrm{Kemp}$, J. M., Powell, T. P. S., The connections of the striatum and globus pallidus: Synthesis and speculation, Phil. Trans. B, 262 (1971) 441-457.

11 König, J. F. R. and Klippel, R. A., The Rat Brain, Kreiger, Huntington, N.Y., 1963.

12 Lammers, H. J., The neural connections of the amygdaloid complex in mammals. In B. E. Elefteriou (Ed.), Neurobiology of the Amygdala, Plenum, New York, 1972, pp. 123-144.

13 Lindroth, P. and Mopper, K., High performance liquid chromatographic determination of subpicomole amounts of amino acids by precolumn fluorescence derivatization with o-phthaldialdehyde, Analyt. Chem., 51 (1979) 1667-1674.

14 Nagy, J. I., Carter, D. A. and Fibiger, H. C., Anterior striatal projections to the globus pallidus, entopeduncular nucleus and substantia nigra in the rat: the GABA connection, Brain Research, 158 (1978) $15 \cdots 29$.

15 Perry, T. L., Hansen, S. and Kloster, M., Huntington's chorea: deficiency of gamma-aminobutyric acid in brain, New Engl. J. Med., 288 (1973) 337-342.

16 Roberts, E., Some thoughts about GABA and the basal ganglia. In M. D. Yahr (Ed.), The Basal Ganglia, Raven, New York, 1976, pp. 191-203.

17 Shinozaki, H. and Konishi, S., Actions of several antihelminthics and insecticides on rat cortical neurons, Brain Research, 24 (1970) 368-371.

18 Shoulson, I., Goldblatt, I., Charlton, M. and Joynt, R. J., Huntington's disease: treatment with muscimol, a GABA-mimetic drug, Ann. Neurol., 4 (1978) 279-284.

19 Uno, M. and Yoshida, M., Monosynaptic inhibition of thalamic neurons produced by stimulation of the pallidal nucleus in cats, Brain Research, 99 (1975) 377-380.

20 Young, A. B., Oster-Granite, M. L., Herndon, R. M. and Snyder, S. H., Glutamic acid: selective depletion by viral induced granule cell loss in hamster cerebellum, Brain Research, 73 (1974) $1-13$. 